\title{
Variable responses of soil pore structure to organic and inorganic fertilization in a Vertisol**
}

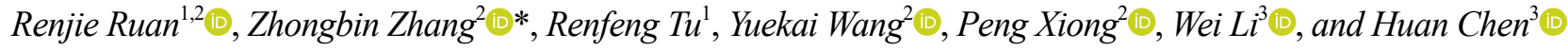 \\ ${ }^{1}$ School of Resources and Environment, Anhui Agricultural University, China \\ ${ }^{2}$ State Key Laboratory of Soil and Sustainable Agriculture, Institute of Soil Science, CAS, NO.71 East Beijing Road, Nanjing, China \\ ${ }^{3}$ Anhui Academy of Agricultural Sciences, China
}

Received April 13, 2021; accepted August 5, 2021

\begin{abstract}
A b s tract. Soil pore structure may become highly variable under different fertilization regimes. This study aims to identify the impacts of long-term fertilization on the soil pore characteristics in a Vertisol and their relationships with water-holding capacity, air permeability and penetration resistance, using X-ray computed tomography. Intact soil cores were sampled from a long-term (37 years) continuous fertilization experiment including treatments with no fertilization (Control), inorganic fertilization, and organic fertilization. The basic soil properties, the three-dimensional characteristics of the macropores, water-holding capacity, air permeability and penetration resistance were all analysed. The results show that, in comparison with the control, the organic fertilization treatment resulted in increased total porosity, macroporosity and porosity with a diameter $>1000 \mu \mathrm{m}$, this was probably due to the increased soil organic carbon content and aggregate stability. The inorganic fertilization treatment had a lower macropore connectivity, air permeability and higher penetration resistance relative to the control, a probable explanation is the decreased aggregate stability resulting from a large amount of dispersing ions in the inorganic fertilizers. Air permeability was positively correlated with macropore connectivity, while water-holding capacity and penetration resistance had no relationship with macropore characteristics. Our findings demonstrate that long-term organic fertilization can improve the macroporosity of Vertisol, while long-term inorganic fertilization has a detrimental effect on soil macropore connectivity.

Keywords: long-term fertilization, computed tomography, pore characteristics, air permeability, penetration resistance
\end{abstract}

*Corresponding author e-mail: zbzhang@issas.ac.cn

**This study was supported by grants from the National Natural Science Foundation of China (NSFC 41771264, 2018-2021 and 41930753, 2020-2024) and Youth Innovation Promotion Association of CAS (2021311, 2021-2024).

\section{INTRODUCTION}

Soil pore characteristics determine solute transport, air and water fluxes, and affect plant water uptake and plant growth (Naveed et al., 2016; Pires et al., 2017). Thus, major research efforts have been devoted to predicting air permeability and saturated hydraulic conductivity under different soil pore structures (Luo et al., 2010; Zhang et al., 2019). Soil pores serve as planes of breakage along which aggregates form, and their sizes and spatial positions determine the micro-environmental conditions for crop root growth (Rabot et al., 2018). It has been shown that continuous macropores are beneficial for crop root growth in compacted soils as the macropores can provide spaces with low resistance and high concentrations of oxygen (Colombi et al., 2017). Therefore, soil pore structures such as macropores should be improved by using favourable agricultural management practices (Sainju et al., 2003).

Soil macropores have been reported to be sensitive to organic fertilization treatment (Xu et al., 2018). It is generally believed that the addition of organic fertilizer increases the soil organic matter content and has a positive effect on soil aggregation and pore system development in a tilled cropping system (Pagliai et al., 2004; Dal Ferro et al., 2013). The increased biological activity resulting from manure application to the soil leads to more continuous biopores, which in turn contributes to increased macroporosity and pore connectivity (Naveed et al., 2014). Zhang

(C) 2021 Institute of Agrophysics, Polish Academy of Sciences 
et al. (2018) also reported that the presence of large-sized biopores in organically fertilized soils changed the soil pore-size distribution and enhanced macroporosity. Many researchers have reported that the application of inorganic fertilizers increases crop root growth and yields, and therefore biomass returns to the field, thus improving soil aggregate stability and the pore system in comparison with an absence of fertilizer treatment (Haynes and Naidu, 1998; Naveed et al., 2014). However, it has also been observed that the application of inorganic fertilizer typically lowers soil $\mathrm{pH}$, adds ions that can disperse soil aggregates, and does not improve the pore structure (Haynes and Naidu, 1998; Guo et al., 2010). For example, Zhou et al. (2017) revealed that inorganic fertilizer application decreased macroporosity and pore surface density because of the degradation of soil aggregates and the reduced number of earthworm burrows. The responses of soil pore characteristics to fertilization treatment are usually inconsistent, this is probably due to the different soil types, climate conditions and additional factors (Tian et al., 2015). Therefore, more studies regarding the effects of long-term fertilization on the three-dimensional pore structure are still required.

In recent years, non-invasive X-ray computed tomography $(\mathrm{CT})$ scanning has been used to directly assess soil pore characteristics and their association with air and water transport properties (Larsbo et al., 2014; Paradelo et al., 2016). It has been established that CT-derived pore characteristics have advantages for the estimation of air, water and solute transport within soils (Katuwal et al., 2015; Guo et al., 2019b). Macroporosity and limiting layer macroporosity have been found to be closely related to air permeability and hydraulic conductivity at a matric potential of $-3 \mathrm{kPa}$ (Naveed et al., 2013). Larsbo et al. (2014) also found significant relationships between macroporosity, macropore surface area, macropore connectivity and water flow. However, the relationships between water-holding capacity, penetration resistance and CT-derived pore characteristics have rarely studied to date.

Vertisols usually have a poor soil structure due to their high clay content and swelling clay minerals, which results in high bulk densities and swelling-shrinkage capacities (Rahman et al., 2017), along with poor water retention and air permeability (Brierley et al., 2011; Kishne et al., 2012). In this study, intact soil cores were collected from three fertilization treatments in a Vertisol: no fertilization as a control (Control), inorganic N, P, K fertilization (NPK) and organic fertilization (OF). An industrial CT scanner was used to examine the soil pore characteristics of the cores. The soil aggregate stability, water-holding capacity, penetration resistance, and air permeability of the samples were also measured. We begin with the hypothesis that long-term fertilization can alter pore characteristics, which will subsequently impact the functions of the soil pore structure. In order to test this hypothesis, the objectives of this study were to: 1) investigate the response of the three-dimensional soil pore characteristics to long-term organic and inorganic fertilization treatments in a Vertisol, and 2) to determine their relationships with water-holding capacity, air permeability and penetration resistance.

\section{MATERIALS AND METHODS}

A long-term fertilization experiment with a cropping system of winter wheat (October to June) and summer maize (June to October) was established in 1981 at the Yangliu Experimental Station $\left(116^{\circ} 23^{\prime} \mathrm{E}, 33^{\circ} 16^{\prime} \mathrm{N}\right.$, elevation $28 \mathrm{~m}$ ) of the Anhui Academy of Sciences in Suixi county, Anhui Province. The mean annual temperature and precipitation of the site is $16^{\circ} \mathrm{C}$ and $750 \mathrm{~mm}$ (Chen et al., 2014), respectively. The soil under investigation is classified as a Vertisol according to the USDA Soil Taxonomy (Soil Survey Staff, 2015).

From this long-term experiment, three fertilization treatments were chosen for this study: no fertilizer (Control), the sole application of chemical fertilizer, $\mathrm{N} 525 \mathrm{~kg} \mathrm{ha}^{-1}$, $\mathrm{P}_{2} \mathrm{O}_{5} 210 \mathrm{~kg} \mathrm{ha}^{-1}, \mathrm{~K}_{2} \mathrm{O} 210 \mathrm{~kg} \mathrm{ha}^{-1}$ (NPK), the sole application of organic bean-cake fertilizer with an equivalent of $\mathrm{N} 525 \mathrm{~kg} \mathrm{ha}^{-1}$ (OF). All three treatments were applied to plots with a size of $30 \mathrm{~m}^{2}$. For the NPK treatment, 33.3\% nitrogen, $50 \%$ phosphorus and $50 \%$ potassium were applied as a base fertilizer and $22.2 \%$ nitrogen (urea) as a topdressing fertilizer during the wheat-growing period, and $16.6 \%$ nitrogen, $50 \%$ phosphorus and $50 \%$ potassium were applied as a base fertilizer and $27.7 \%$ nitrogen (urea) as a topdressing fertilizer during the maize-growing period. For the OF treatment, all of the organic fertilizer was applied annually in the wheat growing season as a base fertilizer. For all treatments, rotary tillage $(0-15 \mathrm{~cm})$ was carried out before wheat sowing and the maize was directly sown after the wheat harvest. Crop residues were removed after harvest with stubble and root biomass left in the soil. Other management practices, including weed control, irrigation and the use of pesticide, etc., were also identical for all of the treatments.

Soil cores were taken from each of the $30 \mathrm{~m}^{2}$ trial plots in October 2018, after the maize harvest. The sampling sites were randomly selected in the middle of the rows of maize. Intact soil cores $(50 \mathrm{~mm}$ in height and $47 \mathrm{~mm}$ in diameter) were sampled using PVC rings from the topsoil $(2.5-7.5 \mathrm{~cm})$ of each treatment plot. The PVC rings were hammered into the soil with a metal handle after the surface soil $(0-2.5 \mathrm{~cm})$ was removed. The soil cores were sealed with plastic film and transported to the laboratory carefully in order to avoid any disturbance or evaporation and weighed before storage in a refrigerator at $4^{\circ} \mathrm{C}$. Seven cores were taken from each fertilization treatment plot, resulting in a total of twenty-one intact cores being collected. Additionally, some mixed soil samples $(0-10 \mathrm{~cm})$ in each fertilization plot were also taken adjacent to each sampling location for the soil cores. 
Two replicates of mixed soils were taken for each treatment in order to measure the soil organic carbon content, total nitrogen content, soil particle-size distribution, $\mathrm{pH}$, cation exchange capacity (CEC) and soil aggregate stability. Soil organic carbon content and total nitrogen content were measured using a CNS Organic Elemental Analyser (Vario MAX, Elementar, Germany). The soil particle-size distribution was measured using a pipette method (Yi, 2009). Soil $\mathrm{pH}$ was determined using a glass electrode with a 1:2.5 soil water ratio. Cation exchange capacity was determined using the ammonium acetate extraction method (Sumner and Miller, 1996). The soil aggregate stability of the sampled soil was measured using a fast wetting technique (Le Bissonnais, 1996). A series of three sieves with 2.0, 0.25, $0.053 \mathrm{~mm}$ openings were used to obtain four aggregate size distributions. Finally, the aggregate stability was estimated using the mean weight diameter $(M W D)$ of each sample,

$$
M W D=\sum_{i=1}^{n} \bar{X} W_{i}
$$

where: $\bar{X}_{l}$ is the mean diameter for each aggregate size, $W_{i}$ is the mass proportion of aggregates remaining on each sieve, and $n$ is the number of sieves.

Four soil cores from each treatment plot were saturated from the bottom for one week before being drained freely in a sandbox for 48 hours to measure the soil water-holding capacity (WHC: $-10 \mathrm{kPa}$ ). Then, the soil water content of the treated soil cores was drained to achieve an approximately $90 \%$ water-holding capacity. The other three cores from each treatment plot were evaluated for water content to ensure that the soil cores reached $90 \%$ of their waterholding capacity. An industrial X-ray CT scanner (Phoenix Nanotom, GE, Sensing and Inspection Technologies, $\mathrm{GmbH}$, Wunstorf, Germany) was used to scan the soil cores using a voltage of $110 \mathrm{kV}$ and a current of $110 \mu \mathrm{A}$, creating 1200 projection images over a $360^{\circ}$ rotation. A $0.2 \mathrm{~mm} \mathrm{Cu}$ filter was used to reduce the beam hardening effect. Datos $\mid \mathrm{x}$ 2.0 software and the filtered back-projection algorithm were used for image reconstruction. For each column after reconstruction, approximately 2200 slices with voxel size $25 \times 25 \times 25 \mu \mathrm{m}^{3}$ were generated.

The resulting greyscale images were first filtered with a 3D Gaussian blur filter to reduce noise using Image J 1.52a software. To remove the edge effect caused by sampling, a region of interest (ROI) of $45 \mathrm{~mm}$ in both diameter and height was selected from the central part of each soil core. The ROI was downsized by a factor of 2 using a bilinear interpolation algorithm to acquire a new ROI with a resolution of $50 \mu \mathrm{m}$ for further image analysis due to the limited computation capacity of the available computer. Segmentation of the greyscale images was performed using Yen's auto thresholding method (Yen et al., 1995, Sezgin and Sankur, 2004). This method considers the image foreground and background to be two different signal sources, so that when the sum of the two class entropies reaches its maximum, the classification number of the grey levels could be classified by minimizing the cost function. The threshold values can then be determined automatically (Yen et al., 1995). The "Auto Threshold" plugin in the ImageJ software processed the full greyscale space, and the threshold of each slice was computed separately. The thresholds varied with different samples. The images were also visually inspected to verify the quality of the segmentation procedure.

After segmentation, pores smaller than 5 voxels were removed to reduce noise by using the "Particle Analysis" plugin of the ImageJ software (Peth et al., 2008). The binary images were analysed to determine a set of macropore structure parameters using the ImageJ software, i.e.: macroporosity, mean diameter $(M D)$, global connectivity $(I)$, specific Euler number $(X v)$, compactness $(C P)$ and the macroporosity of the limiting layer (MPLL). The macroporosity was calculated by dividing the number of voxels classified as macropores $(>50 \mu \mathrm{m})$ by the number of voxels present within the ROI. The diameter of each macropore was determined using a local thickness algorithm in the "BoneJ" plugin of ImageJ (Dougherty and Kunzelmann, 2007). The mean diameter of the macropores $(M W D)$ was then calculated as:

$$
M D=\frac{\sum_{i=0}^{n} D_{i} V_{i}}{\sum_{i=0}^{n} V_{i}}
$$

where: $D_{\mathrm{i}}$ and $V_{\mathrm{i}}$ are the diameter and the volume of each macropore, and $n$ is the number of macropores, respectively. The global connectivity $(\Gamma)$ defines the average degree of connectivity of the macropore networks, which may be calculated as follows:

$$
\Gamma=\frac{\sum_{i=0}^{n}\left(V_{i}^{2}\right)}{\left(\sum_{i=0}^{n} V_{i}\right)^{2}}
$$

when $\Gamma=1$, all macropores are connected in one percolating macropore, and when $\Gamma$ is close to 0 , macropores with a similar size are scattered (Hovadik and Larue, 2007).

The local macropore connectivity is commonly expressed by the function of the number of isolated pores $(\mathrm{N})$, the genus (C), the number of completely enclosed cavities $(\mathrm{H})$, and the Euler number $(\mathrm{N}-\mathrm{C}+\mathrm{H})($ Smet et al., 2018). The Euler number may be determined by using an algorithm calculating voxel neighbourhoods in the "BoneJ connectivity" plugin of ImageJ, then the specific Euler number $(X v)$ may be calculated as follows:

$$
X v=\frac{\sum_{i=0}^{n} \delta x}{V_{r}}
$$

where: $V_{\mathrm{r}}$ is the volume of the ROI and $\delta x$ is the Euler number for each macropore. The more negative the $X v$ is, the more connected the macropore networks (Vogel and Roth, 2001). The compactness of the macropore was defined as follows: 


$$
\text { compactness }=\frac{A^{1.5}}{V}
$$

where: $A$ and $V$ are the surface area and the volume of the macropore, respectively. The compactness is a pore shape factor and is minimized by a sphere (Bribiesca, 2000). The larger the compactness value of a macropore, the more complex is the structure. The mean compactness $(C P)$ was calculated as the volume weighted average of compactness for each macropore:

$$
C P=\frac{\sum_{i=0}^{n} C P_{i} V_{i}}{\sum_{i=0}^{n} V_{i}}
$$

where: $i$ is the index of a macropore, $n$ is the number of macropores, and $V_{\mathrm{i}}$ is the volume of a macropore. The minimum value of macroporosity along the ROI depth (a $50 \mu \mathrm{m}$ depth of each slice) was referred to as the macroporosity of the limiting layer (MPLL). Furthermore, the macroporosity for diameters of 50-100 $\mu \mathrm{m}, 100-300 \mu \mathrm{m}, 300-500 \mu \mathrm{m}$, $500-1000 \mu \mathrm{m}$, and $>1000 \mu \mathrm{m}$ were also calculated (Pagliai et al., 2004). In addition, the total porosity was calculated using the bulk density $(B D)$ :

$$
\text { Total porosity }=1-\frac{B D}{\rho}
$$

where: $\rho$ is the soil particle density (i.e., $2.65 \mathrm{~g} \mathrm{~cm}^{-3}$ ).

After CT scanning, the air permeability of the samples under $90 \%$ water-holding capacity $\left(K_{\mathrm{a} 90}\right)$ was determined using the steady state method (Yi, 2009). The air permeability was calculated according to Darcy's law:

$$
K_{a 90}=\frac{Q L \eta}{A \Delta P}
$$

where: $Q$ is the air flow rate $\left(\mathrm{L}^{3} \mathrm{~T}^{-1}\right), \mathrm{L}$ is the length of the soil sample $(L), \eta$ is the dynamic air viscosity $\left(\mathrm{M} \mathrm{L}^{-1} \mathrm{~T}^{-1}\right), A$ is the cross-sectional area of the soil sample $\left(\mathrm{L}^{2}\right)$, and $\Delta P$ is the pressure difference $\left(\mathrm{M} \mathrm{L}^{-1} \mathrm{~T}^{2}\right)$.

The penetration resistance of the soil cores was measured at a water content of $90 \%$ water-holding capacity using a microcomputer-controlled electronic universal testing machine fitted with a $0.05 \mathrm{~N}$ entrance force (Shenzhen New Sansi Measurement Technology Co. Ltd., Shenzhen, China). A conical steel needle with a $2 \mathrm{~mm}$ diameter at a $60^{\circ}$ angle was inserted vertically into the soil column down to a depth of $40 \mathrm{~mm}$ at a speed of $10 \mathrm{~mm} \mathrm{~min}^{-1}$. Each core was measured three times at different locations. The penetration resistance of the soil is defined as the mean value of the penetration stress measured during the process of needle penetration. Finally, the soil cores were weighed after drying at $105^{\circ} \mathrm{C}$ for $72 \mathrm{~h}$ to obtain their bulk density.

All of the data obtained were checked for normality and homogeneity of variance. Analysis of variance (ANOVA) was performed and means were compared using least significant difference (LSD) at the $\mathrm{p}<0.05$ level. A spearman rank correlation analysis was performed to assess the relationships between soil water-holding capacity, air permeability, penetration resistance and pore characteristics. All of the statistical analyses above were performed by using the SPSS 19.0 Statistical Package. The results are presented as the mean and standard error in tables and figures.

\section{RESULTS}

The SOC of the NPK and OF treatment plots were 46.6 and $67.9 \%$ higher than that of the control treatment plot $\left(8.18 \mathrm{~g} \mathrm{~kg}^{-1}\right)$, respectively (Table 1$)$. The soil was high

Table 1. Basic soil properties of surface soil $(0-10 \mathrm{~cm})$ for three long-term fertilization treatments in a Vertisol

\begin{tabular}{lrrr}
\hline \multicolumn{1}{c}{ Soil properties } & Control & NPK & \multicolumn{1}{c}{ OF } \\
\hline SOC $\left(\mathrm{g} \mathrm{kg}^{-1}\right)$ & 8.18 & 12.00 & 13.70 \\
Total N $\left(\mathrm{g} \mathrm{kg}^{-1}\right)$ & 0.86 & 1.04 & 1.29 \\
Sand $(\%)$ & 4.49 & 4.33 & 4.56 \\
Silt $(\%)$ & 49.90 & 49.70 & 50.50 \\
Clay $(\%)$ & 45.60 & 46.00 & 45.00 \\
pH & 7.54 & 4.95 & 6.67 \\
CEC $(\mathrm{cmol} \mathrm{kg})$ & 29.90 & 33.80 & 30.00 \\
$M W D(\mathrm{~mm})$ & 1.50 & 1.45 & 1.62 \\
\hline
\end{tabular}

Control - no fertilization, NPK - inorganic fertilization, OF - organic fertilization, SOC - soil organic carbon content, $\mathrm{CEC}$ - cation exchange capacity, $M W D$ - mean weight diameter.

in clay content with little variation between the fertilization treatments. The soil $\mathrm{pH}$ was much lower in the NPK-treated plot than in the control and OF plots. The stability of the soil aggregates, as indicated by $M W D$, decreased by $3.33 \%$ after NPK treatment and increased by $8.00 \%$ after OF treatment, relative to the control treatment.

The total porosity was significantly increased by the OF treatment relative to the control treatment (Table 2, $\mathrm{p}<0.05$ ). Macroporosity and $M D$ were significantly higher in the OF-treated soil than in the control and NPK-treated soils. Macropore global connectivity $(I)$ was significantly

Table 2. Effect of long-term fertilization treatments on soil pore characteristics with an analysis of variance (ANOVA)

\begin{tabular}{lccc}
\hline Pore characteristics & Control & NPK & OF \\
\hline Total porosity (\%) & $47.5(0.52) \mathrm{b}$ & $49.0(0.90) \mathrm{ab}$ & $50.4(0.61) \mathrm{a}$ \\
Macroporosity (\%) & $11.9(0.61) \mathrm{b}$ & $12.0(1.11) \mathrm{b}$ & $16.1(1.54) \mathrm{a}$ \\
$M D(\mathrm{~mm})$ & $0.57(0.03) \mathrm{b}$ & $0.55(0.05) \mathrm{b}$ & $0.76(0.08) \mathrm{a}$ \\
$\Gamma$ & $0.85(0.01) \mathrm{ab}$ & $0.79(0.03) \mathrm{b}$ & $0.87(0.02) \mathrm{a}$ \\
$X \nu\left(\mathrm{mm}^{-3}\right)$ & $0.48(0.08) \mathrm{b}$ & $1.03(0.13) \mathrm{a}$ & $0.80(0.16) \mathrm{ab}$ \\
$C P$ & $1726(103) \mathrm{a}$ & $1908(134) \mathrm{a}$ & $1723(87) \mathrm{a}$ \\
MPLL $(\%)$ & $4.24(0.93) \mathrm{a}$ & $4.20(0.56) \mathrm{a}$ & $5.62(0.30) \mathrm{a}$ \\
\hline
\end{tabular}

Different letters indicate a significant difference between the three fertilization treatments using the least significant difference (LSD) test at $p<0.05$, respectively $(n=4)$. Numbers in brackets indicate the standard error of the mean. Control - no fertilization, NPK - inorganic fertilization, OF - organic fertilization, $M D$ - mean diameter of macropore, $\Gamma$ - global connectivity of macropore, $X v$ - specific Euler number of macropore, $C P$ - compactness of macropore, MPLL - macroporosity of limiting layer. 
lower in the NPK-treated plot as compared to that of the OF treatment. The NPK treatment rather than the OF treatment had significantly greater specific Euler numbers $(X v)$ than the control treatment, which suggests that the macropore local connectivity was reduced by the NPK treatment relative to the control treatment.

From the CT-derived three-dimensional images of the soil macropores (Fig. 1), a more complex and denser macropore structure was observed in the OF-treated cores than in the control and NPK-treated cores. For pore sizes of $>1000 \mu \mathrm{m}$, the porosity in the OF-treated soil was significantly higher than in the control and NPK-treated soils (Fig. 2). However, there were no significant differences between all three treatments in terms of porosity for sizes of 50-100, 100-300, 300-500 and 500-1000 $\mu \mathrm{m}$ (Fig. 2).

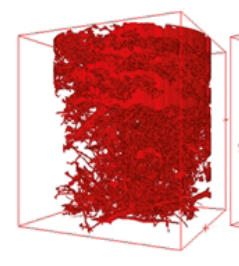

Control

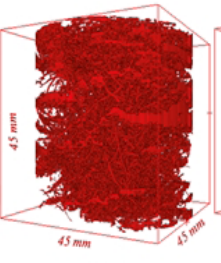

NPK

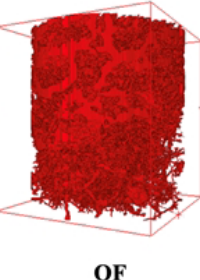

OF
Fig. 1. Three-dimensional computed tomography (CT) images of soil macropores for three fertilization treatments. control - no fertilization, NPK - inorganic fertilization, OF - organic fertilization.

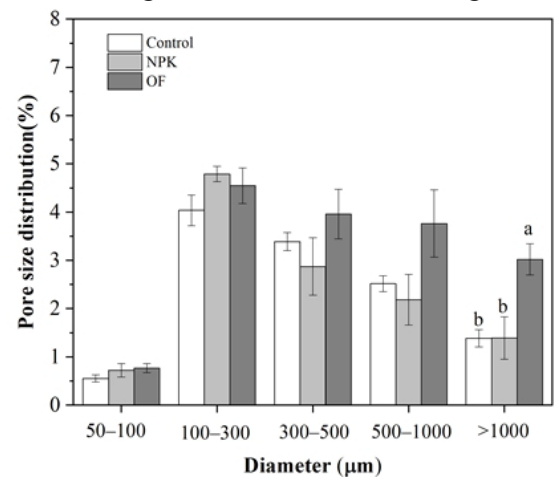

Fig. 2. Porosity for five pore size classes in three fertilization treatments using an analysis of variance (ANOVA). Bars indicate standard errors $(n=4)$. Different letters indicate a significant difference between all of the treatments using the least significant difference (LSD) test at $p<0.05(n=4)$. control - no fertilization, NPK - inorganic fertilization, OF - organic fertilization.

The soil water-holding capacity was not significantly different for the three fertilization treatments (Fig. 3). $\log _{10} K_{a 90}$ was significantly reduced by the NPK treatment relative to the control and OF treatments $(\mathrm{p}<0.05)$. On the contrary, the NPK-treated soil presented a significantly higher penetration resistance than the control and OF-treated soils $(\mathrm{p}<0.05)$.

The WHC was positively correlated with total porosity (Table $3, \mathrm{p}<0.05$ ). Also, $\log _{10} K_{\mathrm{a} 90}$ was only significantly correlated with macropore global connectivity and local connectivity $(\mathrm{p}<0.05)$. There was no significant correlation between these soil pore characteristics and penetration resistance.
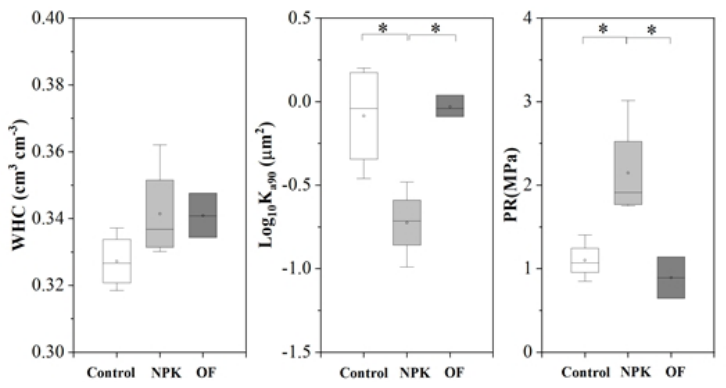

Fig. 3. Soil water-holding capacity (WHC), air permeability under $90 \%$ WHC $\left(K_{\mathrm{a} 90}\right)$ and penetration resistance $(\mathrm{PR})$ under three different fertilization treatments using an analysis of variance (ANOVA). * indicates a significant difference between fertilization treatments using least significant difference (LSD) tests at $\mathrm{p}<0.05$. control - no fertilization, NPK - inorganic fertilization, $\mathrm{OF}$ - organic fertilization.

Table 3. Spearman rank correlation coefficients between WHC, $K_{\text {a90 }}$, PR and soil pore characteristics

\begin{tabular}{lccl}
\hline & $\mathrm{WHC}$ & $\log _{10} K_{\mathrm{a} 90}$ & $\mathrm{PR}$ \\
\hline Total porosity & $0.60^{*}$ & $\mathrm{~ns}$ & $\mathrm{~ns}$ \\
Macroporosity & $\mathrm{ns}$ & $\mathrm{ns}$ & $\mathrm{ns}$ \\
$M D$ & $\mathrm{~ns}$ & $\mathrm{~ns}$ & $\mathrm{~ns}$ \\
$\Gamma$ & $\mathrm{ns}$ & $0.64^{*}$ & $\mathrm{~ns}$ \\
$X v$ & $\mathrm{~ns}$ & $-0.62^{*}$ & $\mathrm{~ns}$ \\
$C P$ & $\mathrm{~ns}$ & $\mathrm{~ns}$ & $\mathrm{~ns}$ \\
MPLL & $\mathrm{ns}$ & $\mathrm{ns}$ & $\mathrm{ns}$ \\
\hline
\end{tabular}

ns - not significant, $*$ - significant correlations at $\mathrm{p}<0.05$, $M D$ - mean diameter of macropore, $\Gamma$ - global connectivity of macropore, $X v$ - specific Euler number of macropores, $C P$ - compactness of macropores, MPLL - macroporosity of limiting layer, WHC - water-holding capacity, $K_{\mathrm{a} 90}$ - air permeability, PR - penetration resistance.

\section{DISCUSSION}

Total porosity was significantly higher in the OF-treated soil than in the control soil (Table 2), which was consistent with a recent study on a Vertisol with a high clay content by Zhou et al. (2020). Furthermore, in our study, the OF treatment resulted in a significantly greater macroporosity than the control and NPK treatments, and this resulted from an increase in the number of large sized macropores (diameter $>1000 \mu \mathrm{m}$ ) (Table 2 and Fig. 2). Zhou et al. (2013) obtained similar results with an Ultisol, and they reported that organic fertilization increased porosity with a diameter $>560 \mu \mathrm{m}$. On account of the increase in large-size macropores, $M W D$ was also increased by the OF treatment. These results may be attributed to the greater degree of aggregate stability and biological activities such as the rooting of crops and burrowing of earthworms (Naveed et al., 2014). The higher organic matter content due to organic fertilization served as a binding agent for macroaggregates, resulting in better soil aggregation (Table 1) and inter-aggregate pore structure (Zhou et al., 2013; Guo et al., 2019a). A recent study found that long-term organic fertilization had a significantly positive influence on biological activities and the formation 
of biopores on an upland soil (Zhang et al., 2018). These results may also partially explain the increase in the volume of large size pores in this study.

In contrast to the OF treatment, the NPK treatment had no positive effect on soil macroporosity relative to the control treatment even though it presented a much greater SOC value (Table 1 and 2). As shown by the specific Euler number, inorganic fertilization exerted negative effects on the local connectivity of macropores (Table 2). This result is in close agreement with recent studies which concluded that the application of inorganic fertilizers affects the pore structure by reducing the connectivity of the pore system as compared with an absence of fertilization (Dal Ferro et al., 2013; Lu et al., 2019). Even though inorganic fertilization treatment increased biomass yield and soil organic matter content, it usually reduced soil aggregate stability (Table 1) by introducing dispersive ions $\left(e . g . \mathrm{NH}_{4}{ }^{+}, \mathrm{K}^{+}\right)$and decreasing soil $\mathrm{pH}$ (Blanco-Canqui and Schlegel, 2013). It was also noted that soil acidification, caused by long-term inorganic fertilization, was harmful to soil fauna activities, and consequently detrimental to the formation of connected macropores (Zhou et al., 2017). An investigation conducted with a corn-soybean rotation soil revealed that aggregated structure and pore structure under NPK treatment were degraded (Singh et al., 2021).

Soil pore characteristics usually have crucial impacts on soil water retention and air permeability (Naveed et al., 2014; Zhang et al., 2019). In this study, the total porosity was significantly correlated to WHC (Table 3 ). It has been reported that OF treatment may increase the water retention of soils by altering pore-size distribution and soil specific surface area because of the higher organic matter content (Naveed et al., 2014). With the increase in organic matter content, the waterholding capacity could also increase and be accompanied by a decrease in total porosity (Zhou et al., 2019).

Our results showed that NPK treatment significantly decreased air permeability relative to the control (Fig. 3). Similar results have revealed that long-term NPK treatment reduces the air flux in soil cores (Zheng et al., 2019). This may be attributed to the significantly lower pore connectivity created by the NPK treatment (Schjønning et al., 2005; Naveed et al., 2014). Our results showed that air permeability was significantly correlated with global connectivity and local connectivity (Table 3). Similarly, Zhang et al. (2019) also demonstrated that macropore connectivity is closely related to air permeability, and it is generally considered that the degree of pore connectivity can be used to predict air permeability to a significant extent (Smet et al., 2018).

Soil penetration resistance significantly increased in the NPK-treated soil as compared to the control soil in this study (Table 2). This result was only consistent with previous studies using a high level of $\mathrm{N}$ input $\left(160 \mathrm{~kg} \mathrm{~N} \mathrm{ha}^{-1}\right)$ treatment (Głąb and Gondek, 2014). Many studies have confirmed that soil penetration resistance is highly correlated with total porosity (Bengough et al., 2006). However, no significant relationship between penetration resistance and total porosity was observed (Table 3 ). This result may be attributed to the lower aggregate stability in the inorganic fertilizationtreated soil relative to the control soil (Table 1). As a result of $525 \mathrm{~kg} \mathrm{ha}^{-1}$ chemical $\mathrm{N}$ input, the inorganic fertilization treatment introduced large amounts of dispersed ions which resulted in the dispersion of soil particles and even in the deterioration of soil aggregates (Haynes and Naidu, 1998). The decrease in aggregate stability can increase soil penetration resistance in long-term fertilized soil (Celik et al., 2010; Nciizah and Wakindiki, 2012).

\section{CONCLUSIONS}

1. X-ray computed tomography scanning toallowed for the assessment of the effect of long-term fertilization on soil pore characteristics.

2. In comparison with the control treatment (no fertilization), organic fertilization ameliorated the total porosity, macroporosity and porosity for diameters $>1000 \mu \mathrm{m}$, while inorganic fertilization resulted in a lower macropore connectivity which was probably due to decreased soil aggregate stability.

3. Air permeability was significantly lower and penetration resistance was significantly greater following the inorganic fertilization treatment as compared with the control treatment.

4. Water-holding capacity was related to total porosity to a significant extent. Air permeability was closely correlated with macropore connectivity.

5. Long-term inorganic fertilization has a detrimental effect on soil aggregation, pore connectivity, air permeability and penetration resistance, whereas organic fertilization can improve soil organic carbon content, soil aggregation and soil pore structure.

Conflicts of interest: The authors declare no conflict of interest.

\section{ACKNOWLEDGEMENTS}

The authors acknowledge the people who helped conduct and maintain the long-term field experiment.

\section{REFERENCES}

Bengough A., Bransby F., Hans J., McKenna S., Roberts T., Valentine T., 2006. Root responses to soil physical conditions; growth dynamics from field to cell. J. Exp. Bot., 57, 437-447, https://doi.org/10.1093/jxb/erj003

Blanco-Canqui H., Schlegel A.J., 2013. Implications of inorganic fertilization of irrigated corn on soil properties: Lessons learned after 50 years. J. Environ, Qual., 42, 861871, https://doi.org/10.2134/jeq2012.0451

Bribiesca E., 2000. A measure of compactness for 3D shapes. Comput. Math. with Appl., 40, 1275-1284, https://doi.org/ 10.1016/S0898-1221(00)00238-8 
Brierley J.A., Stonehouse H.B., Mermut A.R., 2011. Vertisolic soils of Canada: Genesis, distribution, and classification. Can. J. Soil Sci., 91, 903-916, https://doi.org/10.4141/cjss 10060

Celik I., Gunal H., Budak M., Akpinar C., 2010. Effects of longterm organic and mineral fertilizers on bulk density and penetration resistance in semi-arid Mediterranean soil conditions. Geoderma, 160, 236-243, https://doi.org/10.1016/j. geoderma.2010.09.028

Chen H., Cao C., Lingcong K., 2014. Study on wheat yield stability in huaibei lime concretion black soil area based on long-term fertilization experiment. Sci. Agric. Sin., 47, 2580-2590.

Colombi T., Braun S., Keller T., Walter A., 2017. Artificial macropores attract crop roots and enhance plant productivity on compacted soils. Sci. Total Environ., 574, 1283-1293, https://doi.org/10.1016/j.scitotenv.2016.07.194

Dal Ferro N., Charrier P., Morari F., 2013. Dual-scale micro-CT assessment of soil structure in a long-term fertilization experiment. Geoderma 204, 84-93, https://doi.org/10.1016/j. geoderma.2013.04.012

Dougherty R.P., Kunzelmann K., 2007. Computing local thickness of 3D structures with ImageJ. Microsc. Microanal., 13, 1678-1679, https://doi.org/10.1017/S1431927607074430

Guo J.H., Liu X.J., Zhang Y., Shen J., Han W., Zhang W., Christie P., Goulding K., Vitousek P., Zhang F., 2010. Significant acidification in major Chinese croplands. Science, 327, 1008-1010, https://doi.org/10.1126/science.1182570

Guo Z., Zhang J., Fan J., Yang X., Yi Y., Han X., Wang D., Zhu P., Peng X., 2019a. Does animal manure application improve soil aggregation? Insights from nine long-term fertilization experiments. Sci. Total Environ., 660, 1029-1037, https://doi.org/10.1016/j.scitotenv.2019.01.051

Guo Z., Zhang Z., Zhou H., Wang D., Peng X., 2019b. The effect of 34-year continuous fertilization on the SOC physical fractions and its chemical composition in a Vertisol. Sci. Rep., 9, 2505, https://doi.org/10.1038/s41598-019-38952-6

Gląb T., Gondek K., 2014. The influence of soil compaction and N fertilization on physico-chemical properties of Mollic Fluvisol soil under red clover/grass mixture. Geoderma 226-227, 204212, https://doi.org/10.1016/j.geoderma.2014.02.021

Haynes R.J., Naidu R., 1998. Influence of lime, fertilizer and manure applications on soil organic matter content and soil physical conditions: a review. Nutr. Cycl. Agroecosys., 51, 123-137, https://doi.org/10.1023/A:1009738307837

Hovadik J.M., Larue D.K., 2007. Static characterizations of reservoirs: refining the concepts of connectivity and continuity. Petrol. Geosci., 13, 195-211, https://doi.org/10.1144/ 1354 $-079305-697$

Katuwal S., Norgaard T., Moldrup P., Lamandé M., Wildenschild D., de Jonge L.W., 2015. Linking air and water transport in intact soils to macropore characteristics inferred from X-ray computed tomography. Geoderma 237, 9-20, https://doi.org/10.1016/j.geoderma.2014.08.006

Kishne A.S., Ge Y., Morgan C.L.S., Miller W.L., 2012. Surface cracking of a vertisol related to the history of available water. Soil Sci. Soc. Am. J., 76, 548-557, https://doi.org/ $10.2136 /$ sssaj2011.0060
Larsbo M., Koestel J., Jarvis N., 2014. Relations between macropore network characteristics and the degree of preferential solute transport. Hydrol. Earth Syst. Sci., 18, 5255-5269, https://doi. org/10.5194/hess-18-5255-2014

Le Bissonnais Y., 1996. Aggregate stability and assessment of soil crustability and erodibility: I. Theory and methodology. Eur. J. Soil Sci., 47, 425-437, https://doi.org/10.1111/j. 1365-2389.1996.tb01843.x

Luo L.F., Lin H., Schmidt J., 2010. Quantitative relationships between soil macropore characteristics and preferential flow and transport. Soil Sci. Soc. Am. J., 74, 1929-1937, https://doi.org/10.2136/sssaj2010.0062

Lu S., Yu X., Zong Y., 2019. Nano-microscale porosity and pore size distribution in aggregates of paddy soil as affected by long-term mineral and organic fertilization under ricewheat cropping system. Soil Till. Res., 186, 191-199, https://doi.org/10.1016/j.still.2018.10.008

Naveed M., Moldrup P., Arthur E., Wildenschild D., Eden M., Lamandé M., Vogel H.-J., De Jonge L.W., 2013. Revealing soil structure and functional macroporosity along a clay gradient using X-ray computed tomography. Soil Sci. Soc. Am. J., 77, 403-411, https://doi.org/10.2136/ sssaj2012.0134

Naveed M., Moldrup P., Schaap M.G., Tuller M., Kulkarni R., Vogel H.J., Wollesen de Jonge L., 2016. Prediction of biopore- and matrix-dominated flow from X-ray CT-derived macropore network characteristics. Hydrol. Earth Syst. Sci., 20, 4017-4030, https://doi.org/10.5194/hess-20-4017-2016

Naveed M., Moldrup P., Vogel H.-J., Lamandé M., Wildenschild D., Tuller M., de Jonge L.W., 2014. Impact of long-term fertilization practice on soil structure evolution. Geoderma 217, 181-189, https://doi.org/10.1016/j. geoderma.2013.12.001

Nciizah A.D., Wakindiki I.I., 2012. Aggregate stability and strength of a hardsetting soil amended with cattle manure. Afr. J. Agric. Res., 7, 68-73, https://doi.org/10.5897/AJAR11.1271

Pagliai M., Vignozzi N., Pellegrini S., 2004. Soil structure and the effect of management practices. Soil Till. Res., 79, 131-143, https://doi.org/10.1016/j.still.2004.07.002

Paradelo M., Katuwal S., Moldrup P., Norgaard T., Herath L., de Jonge L.W., 2016. X-ray CT-derived soil characteristics explain varying air, water, and solute transport properties across a loamy field. Vadose Zone J., 15, https://doi.org/ 10.2136/vzj2015.07.0104

Peth S., Horn R., Beckmann F., Donath T., Fischer J., Smucker A., 2008. Three-dimensional quantification of intra-aggregate pore-space features using synchrotron-radiation-based microtomography. Soil Sci. Soc. Am. J., 72, 897-907, https://doi.org/10.2136/sssaj2007.0130

Pires L.F., Borges J.A.R., Rosa J.A., Cooper M., Heck R.J., Passoni S., Roque W.L., 2017. Soil structure changes induced by tillage systems. Soil Till. Res., 165, 66-79, https://doi.org/10.1016/j.still.2016.07.010

Rabot E., Wiesmeier M., Schlüter S., Vogel H.-J., 2018. Soil structure as an indicator of soil functions: a review. Geoderma, 314, 122-137, https://doi.org/10.1016/j. geoderma.2017.11.009

Rahman M.T., Zhu Q.H., Zhang Z.B., Zhou H., Peng X., 2017. The roles of organic amendments and microbial community in the improvement of soil structure of a Vertisol. Appl. Soil Ecol., 84-93, https://doi.org/10.1016/j.apsoil.2016.11.018 
Sainju U.M., Whitehead W.F., Singh B.P., 2003. Agricultural management practices to sustain crop yields and improve soil and environmental qualities. Sci. World J., 3, 768-789, https://doi.org/10.1100/tsw.2003.62

Schjønning P., Iversen B.V., Munkholrn L.J., Labouriau R., Jacobsen O.H., 2005. Pore characteristics and hydraulic properties of a sandy loam supplied for a century with either animal manure or mineral fertilizers. Soil Use Manag., 21, 265-275, https://doi.org/10.1111/j.1475-2743.2005.tb00398.x

Sezgin M., Sankur B., 2004. Survey over image thresholding techniques and quantitative performance evaluation. J. Electron. Imaging, 13, 146-166, https://doi.org/10.1117/1.1631315

Singh N., Kumar S., Udawatta R., Anderson S., Jonge L., Katuwal S., 2021. X-ray micro-computed tomography characterized soil pore network as influenced by long-term application of manure and fertilizer. Geoderma, 385, 114872, https://doi.org/10.1016/j.geoderma.2020.114872

Smet S., Beckers E., Plougonven E., Léonard A., Degré A., 2018. Can The Pore Scale Geometry Explain Soil Sample Scale Hydrodynamic Properties? Front. Environ. Sci., 6, https://doi.org/10.3389/fenvs.2018.00020

Soil Survey Staff, 2015. Illustrated guide to soil taxonomy. U.S. Department of Agriculture, Natural Resources Conservation Service, National Soil Survey Center, Lincoln, Nebraska.

Sumner M.E., Miller W.P., 1996. Cation exchange capacity and exchange coefficients. In: Methods of soil analysis (Eds D. Sparks, A. Page, P. Helmke, R. Loeppert, P.N. Soltanpour, M.A. Tabatabai, C.T. Johnston and M.E. Sumner). John Wiley \& Sons, Ltd, Madison, Wisconsin, USA, 1201-1229, https://doi.org/10.2136/sssabookser5.3.c40

Tian K., Zhao Y., Xu X., Hai N., Huang B., Deng W., 2015. Effects of long-term fertilization and residue management on soilorganic carbon changes in paddy soils of China:Ametaanalysis. Agric. Ecosyst. Environ., 204, 40-50, https://doi. org/10.1016/j.agee.2015.02.008

Vogel H.J., Roth K., 2001. Quantitative morphology and network representation of soil pore structure. Adv. Water Resour., 24, 233-242, https://doi.org/10.1016/S0309-1708(00)00055-5
Xu L., Wang M., Shi X., Yu Q., Shi Y., Xu S., Sun W., 2018. Effect of long-term organic fertilization on the soil pore characteristics of greenhouse vegetable fields converted from rice-wheat rotation fields. Sci. Total Environ., 631, 1243-1250, https:// doi.org/10.1016/j.scitotenv.2018.03.070

Yen J.-C., Chang F.-J., Chang S., 1995. A new criterion for automatic multilevel thresholding. IEEE Trans. Image Process., 4, 370-378, https://doi.org/10.1109/83.366472

Yi Y., 2009. Methods for Studying Soil Physics (in Chinese). Peking University Press, Beijing.

Zhang Z., Liu K., Zhou H., Lin H., Li D., Peng X., 2018. Three dimensional characteristics of biopores and non-biopores in the subsoil respond differently to land use and fertilization. Plant Soil, 428, 453-467, https://doi.org/10.1007/s11104 $-018-3689-3$

Zhang Z., Liu K., Zhou H., Lin H., Li D., Peng X., 2019. Linking saturated hydraulic conductivity and air permeability to the characteristics of biopores derived from X-ray computed tomography. J. Hydrol., 571, 1-10, https://doi.org/10.1016/j. jhydrol.2019.01.041

Zheng Y., Han X., Li Y., Yang J., Li N., An N., 2019. Effects of biochar and straw application on the physicochemical and biological properties of paddy soils in Northeast China. Sci. Rep., 9, 16531, https://doi.org/10.1038/s41598 -019-52978-w

Zhou H., Chen C., Wang D., Arthur E., Zhang Z., Guo Z., Peng X., Mooney S.J., 2020. Effect of long-term organic amendments on the full-range soil water retention characteristics of a Vertisol. Soil Till. Res., 202, 104663, https:// doi.org/10.1016/j.still.2020.104663

Zhou H., Fang H., Hu C., Mooney S.J., Dong W., Peng X., 2017. Inorganic fertilization effects on the structure of a calcareous silt loam Soil. Agron. J., 109, 2871-2880, https://doi.org/ 10.2134/agronj2016.10.0590

Zhou H., Fang H., Zhang Q., Wang Q., Chen C., Mooney S.J., Peng X., Du Z., 2019. Biochar enhances soil hydraulic function but not soil aggregation in a sandy loam. Eur. J. Soil Sci., 70, 291-300, https://doi.org/10.1111/ejss. 12732

Zhou H., Peng X., Perfect E., Xiao T., Peng G., 2013. Effects of organic and inorganic fertilization on soil aggregation in an Ultisol as characterized by synchrotron based X-ray microcomputed tomography. Geoderma, 195-196, 23-30, https:// doi.org/10.1016/j.geoderma.2012.11.003 